\title{
Mg-Al- $\mathrm{MoO}_{4}$ layered double hydroxides used as catalysts for the oxidation of styrene
}

\author{
Nguyen Tien Thao", Nguyen Duc Trung, Dang Van Long, Vu Dong Thuc \\ Faculty of Chemistry, Vietnam National University, Hanoi \\ Received 19 September 2016; Accepted for publication 28 August 2017
}

\begin{abstract}
$\mathrm{Mg}$-Al layered double hydroxides have been prepared by the precipitation method and characterized by the physical methods such as XRD, EDS, SEM. The synthesized solids showed the layered hydroxide structure with molybdate and carbonate anions as interlayer compensating anions in the uniform particles. While $\mathrm{Mg}-\mathrm{Al}-\mathrm{CO}_{3}$ is inactive for the liquid oxidation of styrene, $\mathrm{Mg}-\mathrm{Al}-\mathrm{MoO}_{4}-\mathrm{LDH}$ catalyst exhibits a good activity in the conversion of styrene into benzaldehyde and phenyl oxirane. The catalytic activity and product selectivity depend on the reaction conditions and oxidant nature. The styrene conversion is moderate about $10-15 \%$ and the total selectivity to benzaldehyde and styrene oxide reached $99 \%$ as air and $t$-butyl hydrogen peroxide used as milder oxidants.
\end{abstract}

Keywords. Benzaldehyde, styrene, molybdate, hydrotalcite, oxidation.

\section{INTRODUCTION}

Layered double hydroxides (LDHs) are composed of an unusual class of layered materials with positively charged hydroxide layers and charge balancing, mobile anions stayed in the interlayer regions. In details, LDHs have a similar structure to brucite-like $\mathrm{Mg}(\mathrm{OH})_{2}$ sheet where an isomorphous substitution of $\mathrm{Mg}^{2+}$ by a trivalent element $\mathrm{M}^{3+}$ occurs. In brucite, each magnesium cation is octahedrally surrounded by hydroxyl groups [1]. The resulting octahedron shares edges to form infinite sheets. When $\mathrm{Mg}^{2+}$ ions are isoamorphously replaced by a trivalent ion, a positive charge is created in the brucite layer. The positive charge is then compensated by foreign anions in the interlayer sheets $[1,2]$. The layered hydroxide compounds are generally described by the empirical formula $\left(\mathrm{Mg}_{1-x}{ }^{2+} \mathrm{M}^{3+}{ }_{x}(\mathrm{OH})_{2}\right)^{x+}\left(\mathrm{A}^{z-}\right)_{x / z} \cdot n \mathrm{H}_{2} \mathrm{O}$, where $\mathrm{M}^{2+}$ and $\mathrm{M}^{3+}$ are the metal cations, $\mathrm{A}^{z^{-}}$represents the anion needed to compensate the net positive charge $\left(\mathrm{CO}_{3}{ }^{2-}, \mathrm{SO}_{4}{ }^{2-}, \mathrm{MoO}_{4}{ }^{2-} \ldots\right)$, and $n$ is the number of interlayer water molecules [3, 4]. Therefore, layered double hydroxides have aroused considerable interest because of the diversity of their chemical compositions that make them have many practical applications, such as catalysts, catalyst supports, ion exchangers, stabilizers, and adsorbents $[1,5,6]$. As a result, layered double hydroxides have been among the most widely investigated catalyst precursors because of the noteworthy properties of the final catalysts such as a large surface area, basic properties, high metal dispersion, and stability against sintering even under extreme conditions for last decades [1, 3-6].

The aim of this work was to report the preparation of $\mathrm{Mg}-\mathrm{Al}$ layered double hydroxides in which the foreign anions are carbonate or molybdate and to use as catalysts for styrene oxidation under milder conditions. The catalytic performances of the solids were found to be in correlation with the morphology, and structure of the layered double hydroxides, the presence of molybdate ions, and the nature of oxidants.

\section{EXPERIMENTAL}

\subsection{Catalyst preparation and characterization}

$50 \mathrm{~mL}$ of distilled water containing a stoichiometric amount of ammonium heptamolybdate $\left(\left(\mathrm{NH}_{4}\right)_{6} \mathrm{Mo}_{7} \mathrm{O}_{24}\right)$ and $50 \mathrm{~mL}$ of $\mathrm{NaOH}$ solution were added into $500 \mathrm{~mL}$-beaker and magnetically stirred at $65{ }^{\circ} \mathrm{C}$ for $1 \mathrm{~h}$. Then, a quantity of aluminum nitrate nonahydrate and magnesium nitrate hexahydrate dissolved in $150 \mathrm{ml}$ of distilled water was added into the beaker. Aqueous $\mathrm{NaOH}$ solution $(1.5 \mathrm{M})$ was used for the $\mathrm{pH}$ adjustment of 9.0. The sample was then submitted to an aging treatment at $65{ }^{\circ} \mathrm{C}$ for $24 \mathrm{~h}$, followed by filtration, washing with hot distilled water, and drying at $70{ }^{\circ} \mathrm{C}$ for $24 \mathrm{~h}$. The obtained solid was ground into powder. In the case 
of preparation of the $\mathrm{Mg}-\mathrm{Al}-\mathrm{CO}_{3}$ sample, ammonium heptamolybdate was replaced by sodium carbonate.

Powder X-ray diffraction (XRD) patterns were recorded on a D8 Advance-Bruker instrument using $\mathrm{CuK}_{\alpha}$ radiation $(\lambda=1.59 \AA)$. Scanning Electron Microscopy (SEM) Hitachi S-4500 (Japan) with the magnification of 200,000 times. Energy-dispersive spectroscopy EDS) data were obtained from Varian Vista Ax X-ray energy-dispersive spectroscopy.

\subsection{Catalytic performance}

The catalytic oxidation of styrene in N,N'dimethylformamide (DMF) solvent was carried out in a $100 \mathrm{~mL}$ three-neck glass flask fitted with a reflux condenser. For a typical run, $17.4 \mathrm{mmol}$ of styrene, $7.0 \mathrm{~mL}$ of solvent and 0.2 grams of catalyst were loaded into the flask. After the reaction mixture was magnetically stirred and heated to the desired temperature, then $t$-butyl hydrogen peroxide (TBHP, $70 \%$, Sigma Aldrich) or hydrogen peroxide solution $\left(\mathrm{H}_{2} \mathrm{O}_{2}, 30 \%\right)$ was dropped into the flask. As air was used, the flow of air $(5 \mathrm{~mL} / \mathrm{min})$ was conducted into stirred reaction mixture and the reaction time starts being recorded. After the reaction finished, the mixture was cooled down to room temperature and the catalyst was filtered off. The reaction product mixture was then analyzed by gas chromatography and GC-MS (HP-6890 Plus, capillary column HP-5 MS crosslinked PH $5 \%$ PE Siloxane, $30 \mathrm{~m} \mathrm{x} 1 \mu \mathrm{m} \mathrm{x}$ $0.32 \mu \mathrm{m})$.

\section{RESULTS AND DISCUSSION}

\subsection{Textural properties of catalysts}

Two layered double hydroxides with nominal composition formula of $\mathrm{Mg}_{0.7} \mathrm{Al}_{0.3}(\mathrm{OH})_{2}\left(\mathrm{CO}_{3}\right)_{0.15} \cdot \mathrm{xH}_{2} \mathrm{O} \quad\left(\mathrm{MgAl}-\mathrm{CO}_{3}\right)$ and $\mathrm{Mg}_{0.7} \mathrm{Al}_{0.3}(\mathrm{OH})_{2}\left(\mathrm{MoO}_{4}\right)_{0.15} \cdot \mathrm{xH}_{2} \mathrm{O} \quad\left(\mathrm{MgAl}-\mathrm{MoO}_{4}\right)$ have been prepared at a constant $\mathrm{pH}$ conditions. It is noticeable that the purpose of this preparation recipe is to synthesize the same $\mathrm{Mg} / \mathrm{Al}$ molar ratio, but different anions in the interlayer gallery. The X-ray diffraction patterns of the two samples are displayed in Figure 1. It is observed that the two peaks at low 2-theta of $11.2,22.5^{\circ}$ are essentially ascribed to the reflections of basal planes of (003), (006), respectively. The other broad and asymmetric peaks at 2-theta of $34.2,38.2,45.5,60.2,61.3^{\circ}$ are respectively contributed to the reflection signals of (012), (015), (018), (110), and (113) planes. These reflection peaks are typical characteristics for layered double hydroxide structure in which carbonate and molybdate anions are already inserted into the interlayer region [7, 8]. At the same $\mathrm{Mg} / \mathrm{Al}$ molar ratio of $7 / 3$, the XRD pattern for $\mathrm{MgAl}-\mathrm{MoO}_{4}$ sample slightly shifted to the lower reflection angles as compared with that for $\mathrm{MgAl}-\mathrm{CO}_{3}$ solid, indicating a larger interlayer distance between layered hydroxide sheets in the LDH-molybdate material $[1,2,5-8]$.

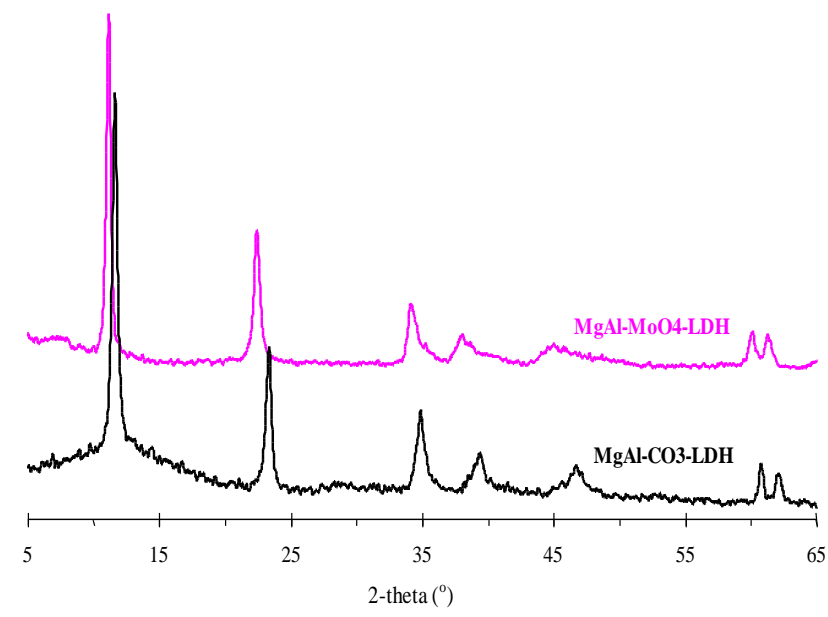

Figure 1: XRD pattern for three solid samples

Since two synthesized samples possess lamellar structure, the presence of all elemental components is screened by EDS technique. Figure 2 elucidated an EDS spectrum for the $\mathrm{MgAl}-\mathrm{MoO}_{4}$ sample.

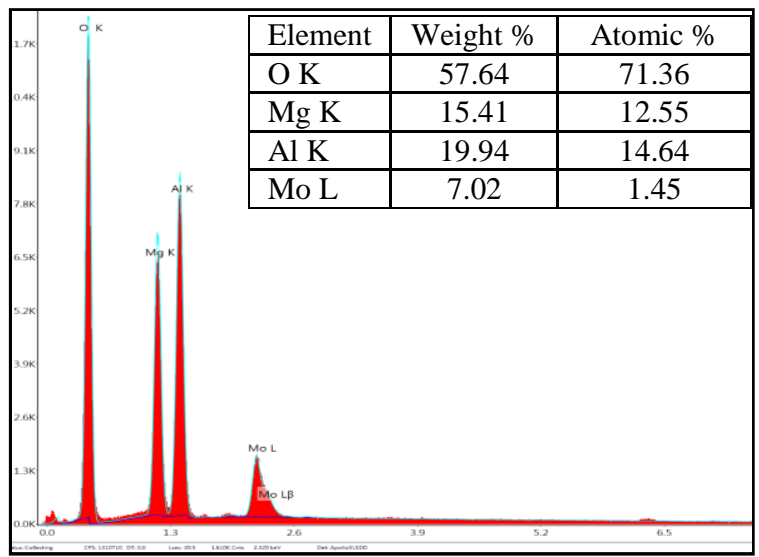

Figure 2: EDS spectrum for $\mathrm{MgAl}_{\text {sample }} \mathrm{MoO}_{4}-\mathrm{LDH}$
sat

Energy-dispersive X-ray spectrometry (EDS) analysis provides local information of the concentrations of different elements in the outermost layers of the catalyst particles. Alumina, magnesium, molybdenum, and oxygen are clearly identified on the solid surface of the sample. Molybdenum metal content is close to the theoretical value, indicating the presence of molybdate as an interlamellar anion in the interlayer regions. 
The catalyst morphology is investigated using scanning electron spectroscopy. Both MgAl - LDH samples show uniform plates with the thickness of $20 \mathrm{~nm}$. The particles lay on each other, giving rise to less porosity. However, $\mathrm{MgAl}-\mathrm{MoO}_{4}$ sample is likely more compactness and thus is expected the lower external surface area [5-7].
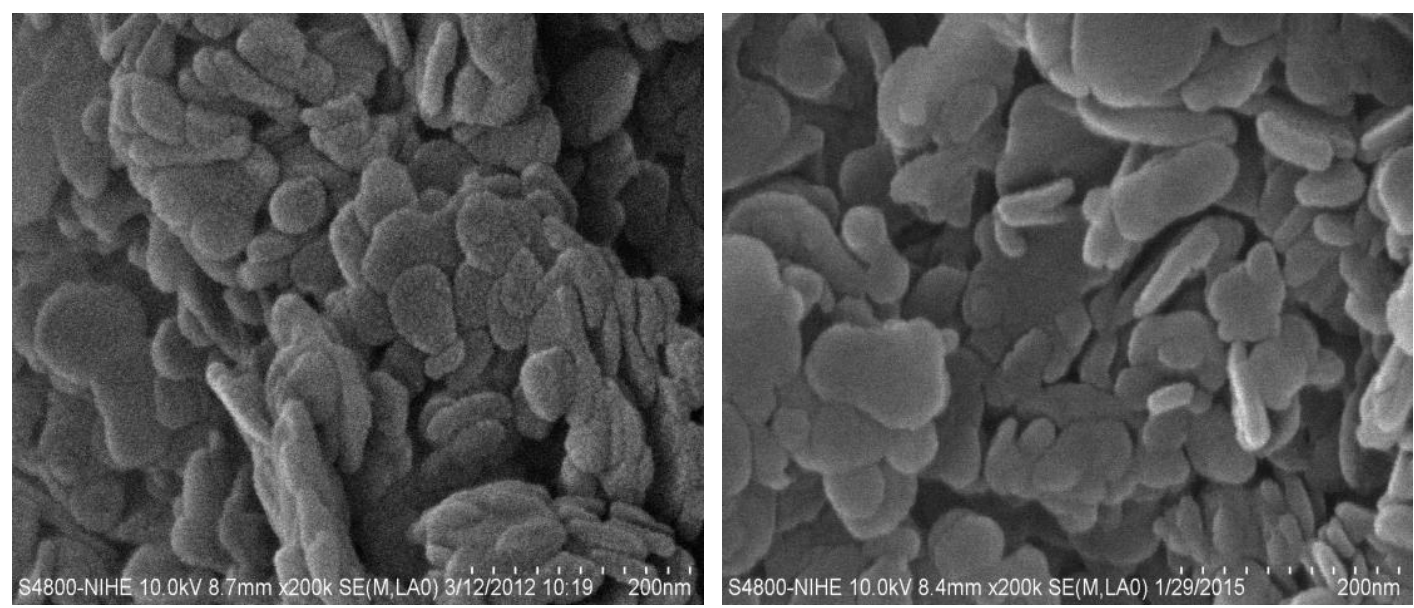

Figure 2: SEM images for $\mathrm{MgAl}-\mathrm{CO}_{3}$ (left) and $\mathrm{MgAl}-\mathrm{MoO}_{4} \mathrm{LDH}$ (right) samples

\subsection{Catalytic activity}

Both Mg-Al LDHs have been tested for the liquid oxidation of styrene in the presence of air. In comparison, a blank test (no catalyst) shows no conversion of styrene. It is noted that $\mathrm{Mo}-\mathrm{Al}-\mathrm{CO}_{3}$ LDH catalysts also gives a very low conversion of styrene and only traces of oxygenated products were detected after 4 hours-reaction time, in good consistent with the literature [6-9]. In contrast, $\mathrm{MgAl}-\mathrm{MoO}_{4} \mathrm{LDH}$ catalyst is added into the reaction mixture flask, the styrene conversion grows significantly up. Indeed, Figure 4 depicted both styrene conversion variation and product distribution of the oxidation at different reaction temperatures. The styrene conversion observably increases with increasing reaction temperature and remains below $20 \%$ at $110{ }^{\circ} \mathrm{C}$ (Fig. 4A). Interestingly, both phenyl oxirane and benzaldehyde are produced in parallel in the reaction temperature range of $90-110{ }^{\circ} \mathrm{C}$ (Fig. 4B) as the major products $[2,7,10,11]$.
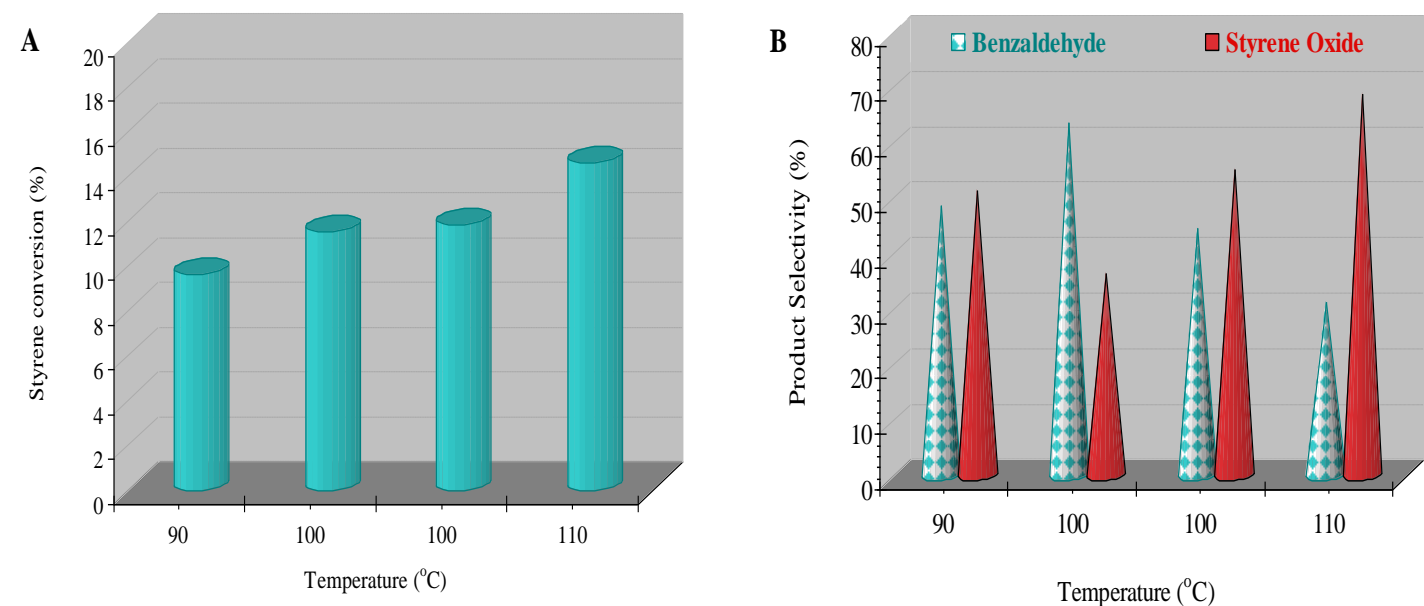

Figure 4: Effect of reaction time on the catalytic activity over $\mathrm{MgAl}-\mathrm{MoO}_{4}-\mathrm{LDH}$ catalyst (DMF solvent, 0.2 grams of catalyst, 4 hours)

The selectivity to benzaldehyde reaches the highest value at $100{ }^{\circ} \mathrm{C}$ and then slightly decreases at the higher temperature while that to styrene epoxide likely increases with the reaction temperature (Fig.
4B). Although the product distribution changes in the reaction temperature, but total selectivity to both benzaldehyde and styrene oxide is almost constant under reported experiments. Thus, it is suggested 
that $\mathrm{Mg}-\mathrm{Al}-\mathrm{MoO}_{4}$ is a very selective catalyst for the liquid oxidation of styrene into valuable oxygenated compounds. Furthermore, figure 4 also reveals that benzaldehyde is produced at a lower temperature while styrene oxide is more favorably yielded at a higher temperature. This is explained by the thermodynamics of the oxidation that the free energy of benzaldehyde $\left(\Delta_{\mathrm{f}} \mathrm{G}_{\text {benzaldehyde }}^{0}=61.2 \mathrm{~kJ} / \mathrm{mol}\right.$, $\left.\Delta_{\mathrm{f}} \mathrm{H}_{\text {benzaldehyde }}^{0}=-36.8 \mathrm{~kJ} / \mathrm{mol}\right)$ is lower than that of styrene epoxide $\left(\Delta_{\mathrm{f}} \mathrm{G}_{\text {styrene oxide }}^{0}=103.5 \mathrm{~kJ} / \mathrm{mol}\right.$, $\left.\Delta_{\mathrm{f}} \mathrm{H}_{\text {styrene oxide }}^{0}=-31.1 \mathrm{~kJ} / \mathrm{mol}\right)[12,13]$.

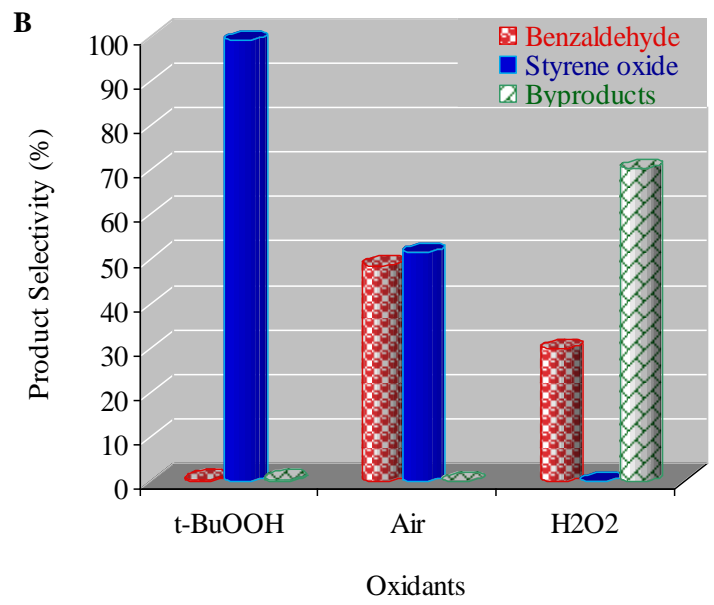

Figure 5: Effects of oxidant nature on catalytic activity over sample $\mathrm{MgAl}-\mathrm{MoO}_{4}-\mathrm{LDH}$ catalyst at $90{ }^{\circ} \mathrm{C}, 4$ hours, air oxidant, DMF solvent, 0.2 grams of catalyst

Moreover, the catalytic activity does not only vary with the reaction temperatures but also depends on the oxidant nature. In practice, Figure $5 \mathrm{~A}$ presents the different catalytic activity as different oxidants are introduced into the styrene reactant. It is worthily noted that three examined oxidants all express the good ability to oxidize styrene over $\mathrm{Mg}$ $\mathrm{Al}-\mathrm{MoO}_{4}$ catalyst, but the styrene conversion decreases as follows of $\mathrm{H}_{2} \mathrm{O}_{2}>$ air > t-BuOOH under the same experimental conditions. Hydrogen peroxide may convert styrene up to $95 \%$, but only a trace of styrene oxide was detected in the product mixture. In this case, benzoic acid and phenyl acetaldehyde, styrene glycol... are mainly formed in addition to $28 \%$ selectivity of benzaldehyde $[10,12$, $14,15]$. Thus, it is suggested that oxidation of styrene with $\mathrm{H}_{2} \mathrm{O}_{2}$ is not selective process in spite of very high activity. Meanwhile, t-BuOOH has displayed a great potential to convert styrene into phenyl oxirane only (Fig. 5B) while air presents the equivalent ability to oxide vinyl benzene into benzaldehyde and styrene epoxide [10, 15-17]. The high activity with $\mathrm{H}_{2} \mathrm{O}_{2}$ oxidant may be related to the formation of $\mathrm{HO} \cdot$ radicals [14].

\section{CONCLUSIONS}

Mg-Al LDH catalysts are successfully prepared by the precipitation method. The synthesized solids showed a good lamellar structure which molybdate and carbonate anions are introduced into the interlayer domains. The catalysts have uniform particle. It was found that only $\mathrm{Mg}-\mathrm{Al}-\mathrm{MoO}_{4}-\mathrm{LDH}$ catalyst is active for the oxidation of styrene and the main products are benzaldehyde and styrene epoxide. The product distribution depends on the reaction conditions and oxidant nature. Air and $t$ butyl hydrogen peroxide are selective oxidants to convert styrene into two valuable products (benzaldehyde and styrene oxide). The styrene conversion is about $10-15 \%$ and the selectivity to the main products of $99 \%$ at $90{ }^{\circ} \mathrm{C}$.

Acknowledgement. This research is funded by Vietnam National Foundation for Science and Technology Development (NAFOSTED) under grant number 104.05-2014.01.

\section{REFERENCES}

1. Vicente Rives. Layered Double Hydroxides: Present and Future, Nova Science Publishers, Inc., 2001.

2. N. Tien Thao, H. Huu Trung. Selective oxidation of styrene over Mg-Co-Al hydrotalcite like-catalysts using air as oxidant, Catal. Commun., 45, 153-157 (2014).

3. Elizabeth Gardner, Thomas J. Pinnavaia. On the nature of selective olefin oxidation catalysts derived from molybdate- and tungstate-intercalated layered double hydroxides, Appl. Catal. A, 167, 65-74 
(1998).

4. Rong-Chang Zeng, Zhen-Guo Liu, Fen Zhang, ShuoQi Li,a Hong-Zhi Cui and En-Hou Han. Corrosion of molybdate intercalated hydrotalcite coating on AZ31 Mg alloy, J. Mater. Chem. A, 2, 13049-13057 (2014).

5. G. Busca, U. Costantino, F. Marmottini, T. Montanari, P. Patrono, F. Pinzari, G. Ramis. Methanol steam reforming over ex-hydrotalcite $\mathrm{Cu}$ Zn-Al catalysts, Appl. Catal. A 310, 70-78 (2006).

6. Nguyen Tien, Thao Le Thi Kim Huyen. Catalytic oxidation of styrene over Cu-doped hydrotalcites, Chemical Engineering Journal, 279, 840-850 (2015).

7. Elizabeth Gardner, Thomas J. Pinnavaia. On the nature of selective olefin oxidation catalysts derived from molybdate- and tungstate-intercalated layered double hydroxides, Appl. Catal. A 167, 65-74 (1998).

8. S. C. Laha and R. Kumar. Selective Epoxidation of styrene to styrene oxide over TS-1 using ureahydrogen peroxide as oxidizing agent, J. Catal., 204, 64-70 (2001).

9. Rodica Zavoianu, Ruxandra Birjega, Octavian Dumitru Pavel, Anca Cruceanu, Mihai Alifanti. Hydrotalcite like compounds with low Mo-loading active catalysts for selective oxidation of cyclohexene with hydrogen peroxide, Appl. Catal. A 286, 211-220 (2005).

10. Y. Wang, Q. Zhang, T. Shishido and K. Takehira. Characterizations of Iron-Containing MCM-41 and Its Catalytic Properties in Epoxidation of Styrene with Hydrogen Peroxide, J. Catal., 209, 186-196 (2002).
11. L. Nie, K. K. Xin, W. Sheng Li, X. Ping Zhou. Benzaldehyde synthesis via styrene oxidation by $\mathrm{O}_{2}$ over $\mathrm{TiO}_{2}$ and $\mathrm{TiO}_{2} / \mathrm{SiO}_{2}$, Catal. Commun., 8, 488492 (2007).

12. B. K. Das, J. H. Clark. A novel immobilised cobalt(III) oxidation catalyst, Chem. Commun., 605606 (2000).

13. N. S. Patil, B. S. Uphade, P. Jana, S. K. Bharagava, and V. R. Choudhary. Epoxidation of styrene by anhydrous $t$-butyl hydroperoxide over reusable gold supported on $\mathrm{MgO}$ and other alkaline earth oxides, $\mathrm{J}$. Catal. 223, 236-239 (2004).

14. J. B. Pedley, R. D. Naylor, and S. P. Kirby. Thermochemical Data of Organic Compounds, 2nd ed., Chapman and Hall, London (1986).

15. Nguyen Tien Thao, Nguyen Duc Trung, Dang Van Long. Activity of molybdate-intercalated layered double hydroxides in the oxidation of styrene with air, Catalysis Letters, 146, 918-928 (2016).

16. Gobinda Chandra Behera, K. M. Parida. Comparative study of molybdenum promoted vanadium phosphate catalysts towards epoxidation of cyclohexene, Appl. Catal. A, 464-465, 364-373 (2013).

17. Nguyen Tien Thao, Nguyen Van Tien, Dang Van Long, Le Thi Kim Huyen. Catalytic activity of cobalt oxides/bentonite in the conversion of styrene, VNU Journal of Science, 30, 263-268 (2014).

18. Cristina I. Fernandes, Silvia C. Capelli, Pedro D. Vaz, Carla D. Nunes. Highly selective and recyclable $\mathrm{MoO}_{3}$ nanoparticles in epoxidation catalysis, Appl. Catal. A, 504, 344-350 (2015).

\section{Corresponding author: Nguyen Tien Thao}

Faculty of Chemistry and Petrochemistry Center

Vietnam National University, Hanoi

No. 19, Le Thanh Tong Str., Hoan Kiem, Hanoi, VIETNAM 1099

E-mail: ntthao@vnu.edu.vn/nguyentienthao@gmail.com

Telephone: +84.043.8253503; Fax: +84.043.824.1140. 